Lucia Maria Guedes

SILVEIRA ${ }^{1}$

Antonio MATERA ${ }^{2}$

Silvia Renata Gaido

CORTOPASSI ${ }^{3}$

Cássio Ricardo Auada

FERRIGNO $^{3}$

José Guilherme XAVIER'

Fernando Malagutti

CUNHA $^{1}$

Correspondências para:

IUCIAMARIAGUEDES SILVEIRA

Rua Carlos Weber, 1389, apto. 32, Vila Hamburguesa-05303-000. São Paulo-SP

Imgsilveira@hotmail.com

Recebido para publicação: 04/11/2003 Aprovado para publicação: 22/06/2005

\title{
Comparação entre os efeitos da associação gelatina- resorcina-formaldeído e do n-butil-2-cianoacrilato na síntese do parênquima hepático de coelhos
}

\author{
1 - Curso de Medicina Veterinária da Universidade Paulista - São Paulo - SP \\ 2 - Curso de Medicina Veterinária da Universidade Anhembi-Morumbi - São \\ Paulo - SP. \\ 3 - Departatamento de Cirurgia, Faculdade de Medicina Veterinária e \\ Zootecnia, Universidade de São Paulo. São Paulo - SP.
}

\begin{abstract}
Resumo
Considerando-se as particularidades anatômicas e funcionais do fígado e a dificuldade da realização de procedimentos cirúrgicos eficientes quanto a hemostasia, estudou-se comparativamente os efeitos de dois adesivos cirúrgicos, gelatina-resorsina-formaldeído e n-butil-2cianoacrilato, como métodos auxiliares na síntese do órgão. A metodologia utilizada determinou rigoroso acompanhamento clínico dos animais estudados, assim como realização de análises macro e microscópica de feridas cirúrgicas experimentalmente induzidas, quanto à evolução do processo cicatricial. Os resultados obtidos demonstraram hemostasia rápida e eficiente em ambos grupos, e alterações celulares e teciduais mais significativas no grupo tratado com n-butil-2-cianoacrilato, quando comparadas àquelas observadas nos grupos controle e gelatina-resorcina-formaldeído. Em relação à proposição estudada, o composto gelatina-resorsina-formaldeído apresentou-se como método alternativo de escolha a ser utilizado nos casos cujas suturas aplicadas isoladamente não proporcionem hemostasia satisfatória.
\end{abstract}

\section{Introdução}

Grande parte dos traumatismos ocorridos em vísceras maciças ocasionam hemorragias parenquimatosas de difícil controle, conduzindo muitas vezes o paciente a morte. Os procedimentos convencionais adotados no reparo de tecido hepático incluem emprego de sutura, sutura com função de ligadura, eletrocoagulação, ressecção parcial e utilização de agentes hemostáticos como esponjas de gelatina e compressas de gaze, aplicados isoladamente ou em combinação ${ }^{1}$. Entretanto, tais técnicas nem sempre são eficazes, justificando a pesquisa de métodos cirúrgicos alternativos, capazes de diminuir a incidência de complicações operatórias.

Os trabalhos desenvolvidos por Braunwald e Tatooles ${ }^{2}$, demonstraram que o adesivo tecidual contendo gelatina- resorcinol polimerizado com uma mistura de aldeído era seguro e eficaz em relação a hemostasia. Esta substância demonstrou elasticidade, força de tensão satisfatória, ação bactericida e nível de toxicidade tecidual diretamente proporcional à quantidade da mistura empregada. A decomposição deste polímero ocorria rapidamente e aparentemente não provocava nenhuma reação orgânica deletéria ou indesejável.

Inou $^{3}$, foi um dos pioneiros na utilização de adesivos a base de cianoacrilato em procedimentos cirúrgicos, obtendo sucesso no reparo de tecidos vivos sem emprego de sutura. Após análises bacteriológicas e toxicológicas, concluiu que o adesivo apresentava ações autoesterilizante e bactericida, proporcionadas por sua estrutura molecular.

Estudos preliminares indicaram que os derivados de cianoacrilato de cadeia mais 


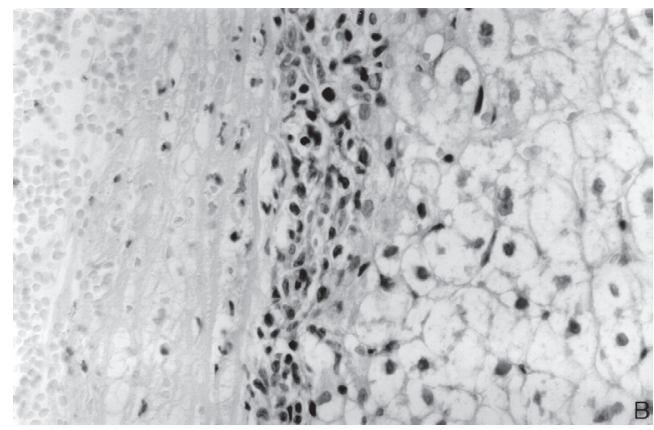

Figura 1 - Fotomicrografia evidenciando a transição entre a área incisada, caracterizada por hemorragia e restos celulares, o infiltrado inflamatório com o predomínio de mononucleares e o parênquima hepático povoado por hepatócitosapresentandodegeneração vacuolar. Hematoxilina eosina (140x)

longa, como os butílicos, eram menos tóxicos e mantinham boas propriedades adesivas e hemostáticas ${ }^{4}$.

A degradação dos derivados de cianoacrilato não esta completamente elucidada. Sabe-se que ocorre produção de metabólitos tóxicos ao organismo, incluindo cianoacetato e formaldeído, ambos tóxicos ao organismo ${ }^{4}$.

O presente trabalho objetivou investigar a viabilidade da utilização dos adesivos cirúrgicos gelatina-resorcinaformaldeído e n-butil-2-cianoacrilato, como auxiliares nas condutas destinadas ao reparo de injúrias traumáticas do parênquima hepático.

\section{Materiais e Métodos}

Foram utilizados 36 animais da espécie leporina (Oryctolagus cuniculis), adultos, raça Nova Zelândia, hígidos, machos e fêmeas, distribuídos em 3 grupos de 12 animais, identificados por A, B e C.

Todos os animais foram submetidos a jejum hídrico e alimentar de uma hora e então, anestesiados mediante administração intramuscular de uma associação de cloridrato de quetamina $5 \%$ e cloridrato de xilazina $2 \%$, em partes iguais, na dose de $0,1 \mathrm{ml}$ para cada 200 gramas de peso corpóreo 5 .

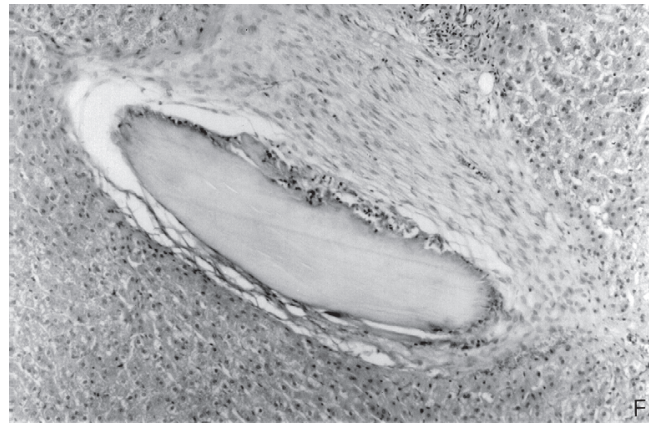

Figura 2 - Fotomicrografia demonstrando o infiltrado inflamatório misto, destacando-se a presença de heterófilos Hematoxilina-eosina (140x)

usuais, a intervenção cirúrgica foi desenvolvida obedecendo-se todas as etapas adiante descritas:

- Laparotomia mediana pré-umbilical de aproximadamente $3 \mathrm{~cm}$ e exposição do fígado;

- Esmagamento digital da porção marginal do parênquima do lobo medial esquerdo, seguida de incisão da cápsula hepática, com auxílio de lâmina de bisturi número 15 , na extensão proximal ao tecido a ser incisado. Separou-se o parênquima ao longo desta linha através de pressão digital.

\section{Grupo A (controle)}

Aplicação de pontos em "U”" separados, com categute simples 5-0, montado em agulha atraumática reta, dispostos de maneira alternada em duas linhas de sutura distantes entre si 0,5 $\mathrm{cm}$, transversalmente ao lobo hepático incisado.

\section{Grupo B}

Aplicação de adesivo cirúrgico a base de gelatina-resorcina-formaldeído*. O preparo da cola foi realizado misturando-se formaldeído com gelatina-resorcina, até adquirir consistência viscosa. As faces da lesão permaneceram comprimidas com compressa de gaze até o momento da aplicação da cola, evitando-se contato da mesma com umidade. A seguir, permaneceram expostas por dois a três minutos.

\section{Grupo C}

Aplicação de adesivo à base de n- 
butil-2-cianoacrilato**. A cola foi retirada da refrigeração e mantida em temperatura ambiente por 30 minutos antes do procedimento. As faces da lesão permaneceram comprimidas com compressa de gaze até o momento da aplicação da cola. A seguir, permaneceram expostas por dois a três minutos.

- Síntese da parede abdominal com fio de nylon 2-0, em pontos simples separados e da pele no mesmo padrão. foi utilizada.

Nenhuma medicação pós-operatória

Após recuperação anestésica, os animais foram identificados e devolvidos às respectivas gaiolas.

\section{Avaliação pós-operatória}

As aferições foram realizadas no $3^{\circ}, 10^{\circ} \mathrm{e}$ $30^{\circ}$ dias após o ato operatório, correspondendo às fases exsudativa, proliferativa e cicatricial, respectivamente 6 . Para cada tempo operatório, foram avaliados quatro integrantes de cada grupo.

Foram executadas avaliação clínica e anatomopatológica (exames macro e microscópico) do parênquima hepático destes animais.

\section{Resultados e Discussão}

\section{Avaliação clínica}

Ao exame físico, segundo os períodos de observação (3, 10 e 30 dias), constatouse que os indivíduos dos grupos $\mathrm{A}, \mathrm{B}$ e $\mathrm{C}$ apresentaram evolução clínica satisfatória. Não foram observados deiscências, infecções, sinais atribuíveis a complicações cirúrgicas ou qualquer outra manifestação clínica que sugerisse comprometimento anatômico e/ou funcional do órgão submetido ao procedimento. A cicatrização cutânea ocorreu adequadamente.

\section{Avaliação anatomopatológica}

\section{Avaliação macroscópica}

O estudo macroscópico das feridas hepáticas, igualmente conduzido dentro dos os grupos de animais, ausência de sinais de infecção, coleções líquidas ou anormalidades do tecido hepático e órgãos adjacentes.

\section{Grupo A}

No $3^{\circ}$ dia após o ato operatório o material de sutura estava presente, não sendo constatadas aderências. Evidenciou-se reação tecidual acima da linha de sutura, sugerindo processo regenerativo. Não foram observadas alterações em órgãos adjacentes ou coleções líquidas em cavidade abdominal.

No $10^{\circ}$ dia, observou-se material de sutura e ausência de aderências. A regeneração completa do parênquima hepático pode ser constatada em todos os animais avaliados.

No $30^{\circ}$ dia, detectou-se reação tecidual de coloração esbranquiçada na região da sutura, sem aderências.

\section{Grupo B}

No $3^{\circ}$ dia pós-operatório, evidenciouse uma camada de coloração esbranquiçada, referente ao adesivo, revestindo totalmente a lesão, além de discreta aderência do epiplon à referida área. Os órgãos adjacentes mantiveramse normais, sem conteúdo líquido em cavidade abdominal.

No $10^{\circ}$ dia, a cola manteve-se presente na superfície hepática, juntamente com discreta aderência do epiplon.

No $30^{\circ}$ dia, a camada de adesivo permaneceu inalterada, assim como a referida aderência regional.

Em todos os tempos de observação, não foram observadas alterações quanto à coloração do parênquima hepático.

\section{Grupo C}

No $3^{\circ}$ dia, foi constatada uma camada transparente correspondente ao adesivo cirúrgico junto à superfície lesada. Evidenciou-se discreta aderência do epiplon à região de aplicação da cola. A coloração do tecido hepático permaneceu inalterada. Não foram observadas coleções líquidas ou alterações em órgãos localizados em cavidade abdominal.

No $10^{\circ}$ dia, mantiveram-se a camada 


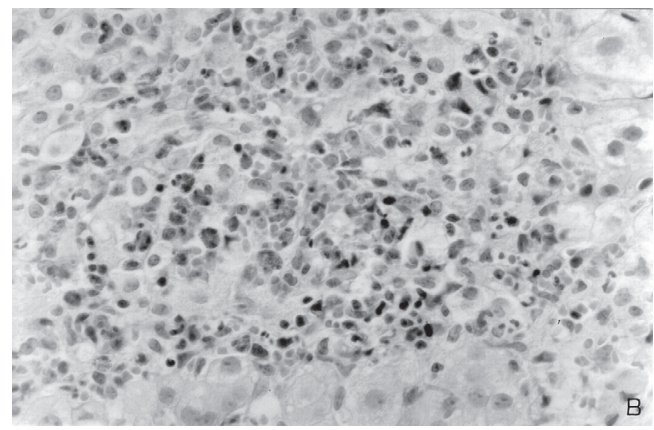

Figura 3 - Fotomicrografia mostrando restos celulares e população predominantemente de polimorfonucleares.

Hematoxilina-eosina (140x)

transparente da cola e a aderência do epiplon.

Após 30 dias do ato operatório, não foram constatadas alterações quanto à coloração do tecido e a cola estava presente juntamente com aderência do omento à região operada.

\section{Avaliação microscópica Grupo A}

O estudo microscópico do tecido hepático dos animais pertencentes a este grupo, realizado no $3^{\circ}$ dia após a cirurgia, indicou hemorragia seguida de necrose discreta e infiltrado inflamatório misto focal, com predomínio de células mononucleares (Figura 1).

No $10^{\circ}$ dia, observou-se eventual persistência de zona necrótica, fibrose e infiltrado inflamatório misto moderado, com predomínio de células mononucleares e alguns granulomas compostos de células gigantes tipo corpo estranho, além de proliferação ductal.

Aos 30 dias, evidenciou-se fibrose ao redor do fio de sutura. Constatou-se também, infiltrado inflamatório mononuclear discreto e persistência de reações granulomatosas (Figura 2).

Identificou-se degeneração vacuolar moderada dos hepatócitos e presença do fio de sutura em todos os tempos de observação.

\section{Grupo B}

No $3^{\circ}$ dia pós-operatório, a análise

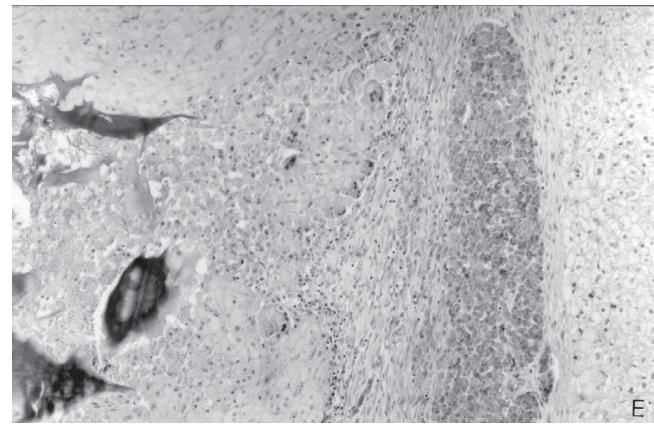

Figura 4 - Fotomicrografia evidenciando reação fibrótica ao redor do fio de sutura, em meio a parênquima hepático degenerado. Hematoxilina-eosina (34x)

histopatológica de tecido hepático destes animais, revelou áreas hemorrágicas com necrose de coagulação ao longo de toda superfície de contato do composto gelatinaresorcina-formaldeído com este tecido. Nas porções mais profundas destas amostras, observou-se degeneração vacuolar discreta dos hepatócitos com infiltrado inflamatório misto moderado (Figura 3).

No $10^{\circ}$ dia, na interface entre a cola e o parênquima hepático, identificou-se uma faixa de tecido fibrótico infiltrado por leucócitos mononucleares e heterófilos, associada a ocasionais células gigantes. Logo abaixo, caracterizou-se tecido hepático apresentando degeneração vacuolar moderada.

No $30^{\circ}$ dia, constatou-se degeneração vacuolar variando de moderada a intensa, necrose discreta com fibrose moderada e infiltrado inflamatório discreto formado por células mononucleares e gigantes, dispostas ao redor das áreas de necrose (Figura 4).

\section{Grupo C}

Nas análises histopatológicas conduzidas no tecido hepático dos animais deste grupo, o polímero a base de n-butil-2-cianoacrilato permaneceu incolor. Artefatos e/ou irregularidades teciduais puderam ser visualizados em regiões nas quais o polímero foi aplicado.

No $3^{\circ}$ dia após o ato operatório, evidenciou-se hemorragia, necrose liquefativa intensa com degeneração vacuolar de 


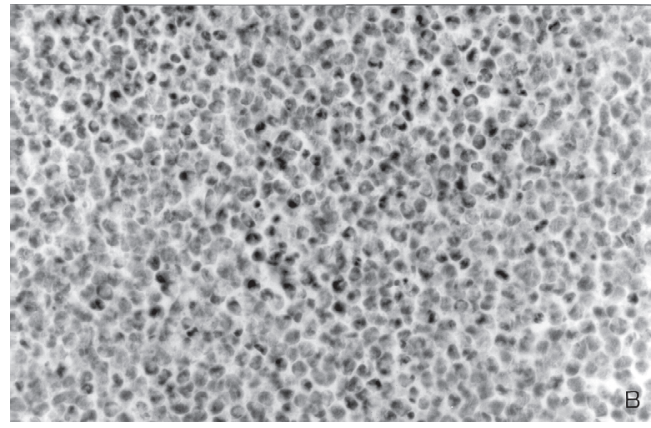

Figura 5-Fotomicrografia evidenciando a presença de restoscelulares e população fagocítica em meio a cola, constituindo eventualmente células gigantes. Logo abaixo identifica-se fibrose, área siderótica e parênquima hepático degenerado. Hematoxilina-eosina (34x)

hepatócitos discreta, proliferação ductal e infiltrado inflamatório misto muito intenso, com predomínio de polimorfonucleares $\mathrm{e}$ eventuais células mononucleares (Figura 5).

No $10^{\circ}$ dia, identificou-se intensa fibroplasia, infiltrado inflamatório misto moderado com presença de células gigantes e degeneração vacuolar moderada a intensa.

No $30^{\circ}$ dia, constatou-se agravamento do processo fibrótico, associado à congestão vascular local e infiltrado inflamatório discreto, composto por células mononucleares e ocasionais heterófilos, além de células gigantes tipo corpo estranho. O padrão de degeneração vacuolar dos hepatócitos manteve-se semelhante ao tempo anterior (Figura 6).

A avaliação macroscópica demonstrou que os compostos estudados mantiveram, em todos os animais e seus respectivos períodos de observação, sua propriedade adesiva apenas sobre as superfícies em reparo. Resultados semelhantes foram obtidos em experimentos prévios $^{2,7,8}$

Registros preliminares indicaram que procedimentos utilizados no reparo de parênquima hepático nem sempre são eficazes, possibilitando a ocorrência de complicações pós-operatórias como hemorragia, infecções e disfunções hepáticas ${ }^{9}$. No trabalho em questão, a hemostasia completa foi obtida nos três grupos antes do fechamento da cavidade. Nos grupos B e C, a hemostasia ocorreu quase que imediatamente após a aplicação dos adesivos

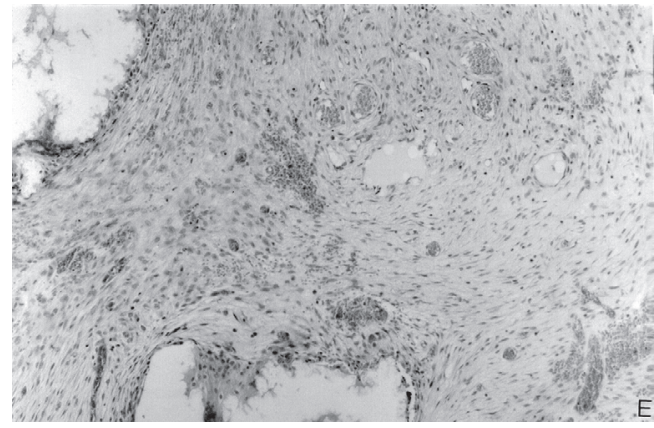

Figura 6 - Fotomicrografia mostrando extensa fibrose tecidual coma persistência da reação da cola. Hematoxilina-eosina (34x)

sobre a superfície lesada. No grupo A, o sangramento inicial foi diminuindo até total hemostasia com a aplicação de linha de sutura. O sangramento citado no referido trabalho e observado na presente pesquisa, apenas retardou e dificultou o procedimento, prolongando o tempo cirúrgico e não demonstrou as complicações citadas pelos autores.

Alguns autores destacaram que as principais vantagens da utilização de adesivos cirúrgicos em relação a outros métodos, incluem a diminuição do tempo cirúrgico, rapidez e eficiência na promoção de hemostasia ${ }^{7,8,10}$. Experimentos realizados com gelatina-resorcina-formaldeído em lesões hepáticas de cães demonstraram bons resultados quanto aos efeitos hemostáticos proporcionados por este composto ${ }^{8,11}$. Orda et al. ${ }^{9}$, empregaram o n-butil-2-cianoacrilato em lesões hepáticas, confirmando a hemostasia imediata após aplicação do adesivo. Os resultados verificados nesta pesquisa foram concordantes com estes dados.

No presente estudo, não foram observados sinais clínicos que sugerissem infecções decorrentes do uso dos adesivos. Cabe ressaltar que tais materiais não sofreram nenhum processo prévio de esterilização, sugerindo ação auto-esterilizante dos mesmos, tal como descrito por outros pesquisadores ${ }^{9,12}$. Entretanto, investigações preliminares realizadas por Page e Borick ${ }^{13}$, não obtiveram dados conclusivos que 
atribuíssem propriedades antimicrobianas aos referidos compostos.

Neste trabalho, as reações teciduais mais consistentes ocorreram aos 3 e 10 dias de observação e caracterizaram-se pela semelhança de fenômenos descritos nos experimentos realizados por outros pesquisadores ${ }^{7,14,15,16}$. Em relação aos grupos A e B, a resposta celular não apresentou diferença relevante. $\mathrm{O}$ grupo A demonstrou processo inflamatório discreto, determinando regeneração do parênquima hepático observada no $30^{\circ}$ dia após o ato operatório. $O$ grupo $B$ apresentou reação tecidual semelhante ao grupo A, sendo observada fibrose discreta próxima à região de aplicação da cola no $30^{\circ}$ dia de observação. Em relação à reação tecidual proporcionada pelo n-butil-2-cianoacrilato, em todos os tempos de observação a resposta celular foi bastante intensa, permitindo presumir a existência de histotoxicidade determinada pela aplicação do produto. Comparandose os grupos $\mathrm{A}$ e $\mathrm{B}$ ao $\mathrm{C}$, observou-se que o grupo $\mathrm{C}$ no $3^{\circ}$ dia apresentou reação necrótica e inflamatória intensa, determinando agravamento do processo fibrótico. Em relação aos grupos B e C, alterações microscópicas foram evidenciadas apenas no lóbulo hepático no qual foram aplicadas as colas, sem comprometimento de áreas adjacentes ao tecido hepático lesado. Tais achados confirmam os relatos de outros estudiosos ${ }^{7,16,17}$.

O mecanismo de histotoxicidade desencadeado por adesivos cirúrgicos tem sido discutido, sendo improvável relacioná-lo ao calor produzido na reação de polimerização. Metabólitos tóxicos produzidos pela degradação destas substâncias podem ser responsáveis pela toxicidade tecidual. Estudos preliminares demonstraram que adesivos cirúrgicos podem persistir nos tecidos durante meses ou até anos após sua utilização. Considerando-se este fato, especula-se a existência de possíveis efeitos carcinogênicos, não havendo confirmação de tais eventos em estudos anteriormente apresentados $s^{4,8,12,16,17,18}$. No presente trabalho, não foi possível estabelecer uma relação precisa entre histotoxicidade e carcinogênese, dado o curto período de observação dos animais no experimento.

\section{Conclusões}

Os resultados obtidos após a realização desta pesquisa, permitiram admitir as seguintes conclusões:

- Os compostos gelatina-resorcinaformaldeído en-butil-2-cianoacrilato produziram hemostasia rápida e adequada, mantendo seu poder adesivo por todo período do estudo (30 dias).

- On-butil-2-cianoacrilato proporcionou alterações citohistopatológicas mais intensas quando comparadas àquelas desencadeadas pela ação da mistura gelatina-resorcina-formaldeído;

- $O$ infiltrado polimorfonuclear (heterófilos) e necrose intensa constatados aos 3 e 10 dias de observação no grupo de animais que recebeu n-butil-2-cianoacrilato, decorreram de provável histotoxicidade desencadeada por este produto;

- Comparativamente às proposições estudadas, acredita-se que no reparo do tecido hepático gelatina-resorcina-formaldeído possa representar a alternativa de escolha nos casos em que as suturas aplicadas isoladamente não proporcionem hemostasia satisfatória.

\section{Comparison between the effects of the compound gelatin-resorsin- formaldeide and the n-butil-2-cianoacrilate in hepatectomy in rabbits}

\section{Abstract}

There are difficulties in liver surgical procedures, specifically hemostasis, due to anatomic and functional characteristics of this organ. Considering these factors, this study compared the effect of two

\section{Key-words:}

Adhesives.

Gelatin-resorsin-

formaldeíde.

Cianoacrilate.

Liver. 
surgical adhesives, gelatin-resorcin-formaldeíde and n-butil-2cianoacrilate, in the liver synthesis. Clinical evolution of the animals utilized in this study and cicatrization of experimental liver surgical wounds were investigated. Cicatrization was analysed by macroscopic and microscopic evaluation. Results demonstrated fast and efficient hemostasis in both groups, and more important cellular and tissue alterations on the animals treated by n-butil-2-cianoacrilate, when this group was compared to the control and gelatin-resorcinformaldeíde groups. Considering the purpose of this study, gelatinresorcin-formaldeíde compound was the best alternative method on cases where the sutures employed alone had failed to provide adequate hemostasis.

\section{Referências}

1 PRAUSE, J. U.; JENSEN, O. A. Studies on human corneal ulcers treated with histoacrylic glue. Acta Ophthalmology, v. 60, n. 4, p. 547-556, 1982.

2 BRAUNWALD, N. S.; TATOOLES, C. J. The use of crosslinked gelatin tissue adhesive to control hemorrhage from liver and kidney. Surgery Forum, $v$. 16, n. 1, p. 345-346, 1965.

3 INOU, T. Studies on the surgical use of plastic adhesives. American Journal of Proctology, v. 13, n. 4, p. 219-226, 1962.

4 WILKINSON, T. S. Tissue adhesives in cutaneous surgery. Archives of Dermatology, v. 106, n. 6, p. 834-836, 1972.

5 AESCHBACHER, G. Rabbit anesthesia. Compendium on Continuing Education, v. 17, n. 8, p. 1003-1011, 1995.

6 INÁCIO, W. et al. Anastomose esôfago-esofágica cervical com adesivo butil-2-cianoacrilato e fio de algodão em dois planos de sutura. Revista do Colégio Brasileiro de Cirurgiões, v. 14, n. 3/4, p. 101-104, 1987.

7 BIONDO-SIMÕES, M. L. P. et al. Uso de adesivo em trauma hepático: estudo experimental em ratos. Acta Cirúrgica Brasileira, v. 8, n. 1, p. 24-27, 1993.

8 ZEPLIN, H. E. Surgery of aortic dissections with GRF glue. Annals of Thoracic Surgery, v. 54, n. 6, p. 1248 1249, 1992.

9 ORDA, R. et al. Repair of hepatic and splenic injuries by autoplastic peritoneal patches and butyl-2cyanoacrylate monomer. Journal of Surgical Research, v. 17, n. 6, p. $365-374,1974$

10 BORST, H. G.; LAAS, J.; BUHNER, B. Efficient tissue gluing in aortic dissection. European Journal of Cardio-Thoracic Surgery, v. 8, n. 3, p. 160-161, 1994.

11 TORIUMI, D. M. et al. Variable histotoxicity of histoacryl when used in a subcutaneous site: an experimental study. Laryngoscope, v. 101, n. 4, p. 339-
343, 1991.

12 TORIUMI, D. M. et al. Histotoxicity of cyanoacrylate tissue adhesives: a comparative study. Archives Otolaryngology Head Neck Surgery, v. 116, n. 5, p. 546-550, 1990.

13 PAGE, C. R.; BORICK, P. M. Contamination and recovery of bacterial spores from methyl-2-cyanoacrylate monomer. Archives of Surgery, v. 94, p. 162, 1967.

14 COOPER, C. W.; FALB, R. D. Surgical adhesives. Annals of New York Academy of Sciences, v. 146, p. 214-224, 1968.

15 TATOOLES, C. J.; BRAUNWALD, N. S. The use of crosslinked gelatin as a tissue adhesive to control hemorrhage from liver and kidney. Surgery, v. 60, n. 4, p. 857-861, 1966.

16 VÁNDOR, E. et al. Experiences about the application of gelatin-resorcinol-formaldehyde tissue adhesive in experimental ruptured liver injury. Zeitschrift fur Experimentelle Chirurgie, v. 13, n. 1, p. 52-58, 1980.

17 MACLACHLAN, N. J.; CULLEN, J. M. Fígado, sistema biliar e pâncreas exócrino. In: CARLTON, W. W.; MC GAVIN, M. D. Patologia veterinária especial. Porto Alegre: Artmed, 1998. p. 95-125.

18 FOSSUM, T. W. Small animal surgery. St. Louis: Mosby, 1997. 1195 p. 